\title{
Social Comparison as Mediator: Does Instagram Intensity Predict Self-Esteem?
}

\author{
Shila Kinnari Nayenggita \\ Fakultas Psikologi Universitas Katolik Indonesia Atma Jaya \\ shila.nayenggita@outlook.com \\ Made Syanesti Adishesa \\ Fakultas Psikologi Universitas Katolik Indonesia Atma Jaya \\ syanes.adishesa@atmajaya.ac.id
}

\begin{abstract}
Instagram is one of the social media platforms that allow people to compare themselves with others (social comparison). Seeing the popularity of SNS, this study explores the role of social comparison as a mediator of the influence of Instagram usage intensity on users' self-esteem. The study was conducted using a mediation test technique through the PROCESS program, with 158 participants $(25.95 \%$ male and $74.05 \%$ female) in the age range $18-25$ years ( $M=$ $21.53, \mathrm{SD}=1.21)$. The measurement tools used were the Rosenberg Self-Esteem Scale (RSES), questions relating to social comparison behavior on Instagram, and the average duration spent using Instagram. The findings show that downward social comparison did not act as a mediator in predicting the influence of Instagram usage on young adults' self-esteem. On the contrary, our findings suggested upward social comparison mediate the relationship between Instagram usage and self-esteem. The implication of this study will be further discussed.
\end{abstract}

Keywords: social comparison, self-esteem, emerging adulthood, Instagram

Received 23 September 2020/Accepted 9 March 2021 @Author all rights reserved

\section{Introduction}

The rapid development of the internet turned social networking sites (SNS) into an integral part of individuals' everyday life. SNS is one of the communication media that allows users to interact by sharing personal information, making a connection, and exchanging messages (Kaplan \& Haenlein, 2010). The presence of various SNS types, including Instagram, made it easier for people to communicate indirectly. Nowadays, Instagram has become the most popular SNS used by people from every age and background based on the significant amount of active users (Herman, 20I4). 
In spite of its popularity, studies have shown Instagram usage may bring detrimental effects to its user especially teenagers. Compared to other SNS such as YouTube, Twitter, Facebook, and Snapchat, a study by Royal Society for Public Health (2017) found Instagram as the most harmful SNS to mental health among teenagers. A more recent study in Indonesia also found higher Instagram usage to be associated with low self-esteem (Evelin \& Adishesa, 2020). The study also indicates different activities have different association with self-esteem. Editing one's Instagram profile is associated with lower self-esteem, but communicating with friends is associated with higher self-esteem. This result suggests there is more than meets the eye when it comes to adverse effects of Instagram usage. Instagram usage may not directly affect self-esteem, but through mediation of other variable.

Rosenberg and Egbert (Jackson \& Luchner, 2018) stated that Instagram motivates users to show the best part of their lives to be accepted by followers in comments and the number of likes received in the virtual world. This condition is facilitated by Instagrams' template, which allows users to build their self-presentation in social media (Lupinetti, 20I5). On Instagram, every user has a space to manage and edit content before being made public. In other words, Instagram users are given space to consciously decide what type of content they would like to show the public. The majority of content can be accepted well and is socially desired by followers. As an implication, it causes Instagram users to be easily exposed to others' posts that show their ideal self (Rosenberg \& Egbert in Jackson \& Luchner, 2018). Exposure to socially desirable content could increase the tendency for someone to make a social comparison.

The strong relationship between SNS with humans' social function provides a strong basis for social comparison to appear (Vogel, Rose, Roberts, \& Eckles, 2014). This fact is caused by the function of SNS that allows individuals to show details of their life and experience, post personal pictures, maintain social interaction, plan social events, meet new people, observe others' life, fulfill the need for belongingness, an express trust, preference, and emotion (Boyd \& Ellison, 2007; Tosun, 2012; Nadkarni \& Hofmann, 20I2; Ivcevic \& Ambady, 2012). Individuals are assumed to have a strong drive to compare themselves to others because it is a way to fulfill one's need for affiliation, self-evaluate, make decisions, feel inspired, and regulate emotion and wellbeing (Festinger, 1954). 
Instagram, as an SNS, provides plenty of opportunities for individuals to make social comparisons online. According to Festinger (Rinn, Jamieson, Gross, \& McQueen, 2009), individuals can compare themselves to others in both upward and downward. Upward social comparison happens when individuals compare themselves with someone superior in terms of their positive characteristics. On the contrary, downward social comparison happens when a person compares themselves with someone who is more inferior or has negative characteristics (Wills, 198I; Wood, 1989 in Vogel et al., 2014). Based on that explanation, the process of social comparison that Instagram users do can be described. People could make an upward social comparison with a famous artist or role models that they admire. On the other hand, individuals could also use a downward social comparison with other users whom they deemed unattractive or have fewer followers than them.

As the use of SNS increases, Vogel et al. (2014) stated that most social comparisons are in the form of downward social comparison. This situation exists because Instagram users tend to show their best selves on Instagram. Although upward social comparison can inspire individuals to be better by having the person they view as a role model, however, it could also elicit feelings of being not good enough and having negative self-evaluation (Morse \& Gergen, 1970; Marsh \& Parker, 1984; Pyszczynski, Greenberg, \& LaPrelle, 1985; Lockwood \& Kunda, 1997 in Vogel et al., 2014). Meanwhile, although downward social comparison could negatively influence someone to focus on negative things, it could also improve emotion and self-evaluation (Wills, I98I; Aspinwall, 1997 in Vogel et al., 2014).

Several past studies have focused on the consequence of social comparison in social media. Those studies' findings have revealed that social media comparison could predict depressive tendencies and low life satisfaction (Krasnova, Wenninger, Widjaja, \& Buxmann, 20I3; Feinstein, et al., 2013; Nesi \& Prinstein, 20I5, in Bergagna \& Tartaglia, 20I8). Further, the upward social comparison could be due to high exposure to social media that could disrupt self-evaluation (Vogel et al., 20I4). High usage of social media is also associated with an increase in depressive symptoms and a decline in wellbeing (Mehdizadeh, 2010; Kalpidou, Costin, \& Morris, 20I I; Kross et al., 20I3; Rutledge, Gillmor, \& Gillen, 20I3; Feinstein et al., 2013 in Vogel et al., 20I4). These negative impacts could disrupt the self-evaluation and selfesteem of the user if not properly handled. 
The self-esteem of users can be negatively influenced by strangers in social media or due to receiving negative comments on their social media (Acar, 2008; Valkenburg, Peter, \& Schouten, 2006 in Chou \& Edge, 2012). Self-esteem refers to the positive and negative evaluation that one does of themselves, meaning that it is how far a person considers themselves to be enough or competent (Coopersmith in Vogel et al., 20I4).

Previous study (Evelin \& Adishesa, 2020) hypothesized that the intensity of Instagram usage is not the only factor that could explain the low self-esteem in users. How individuals use Instagram may have different effects on self-esteem. Based on previous literature, we hypothesized activities in which social comparison is triggered would be more harmful to one's self-esteem. Thus, this study will examine the role of social comparison on the influence that Instagram usage has on users' self-esteem.

\section{Method}

\section{Participants}

The study was conducted using a mediation test design through the PROCESS program with model number four. There were I58 participants (25.95\% male and $74.05 \%$ female) in the age range $18-25$ years $(M=21.53, S D=1.21)$ obtained through convenience sampling.

\section{Questionnaires}

This study's measuring instrument is the Rosenberg Self-Esteem Scale (RSES), which contains ten statements and has been adapted to Indonesian, two questions about social comparison behavior on Instagram, and the average duration of Instagram users' usage during the past week in minutes.

In this study, each participant was given a link to the Cognito form consisting of a demographic questionnaire, questions about the use of Instagram, the Rosenberg SelfEsteem Scale (RSES) measurement tool, and questions about the social comparison. An explanation regarding the measurement of the variables is given below. Informed consent is available on the start page of the form, which contains a description of the research and the right that each participant has to withdraw at any time if they are willing to participate. At 
the end of the informed consent, prospective participants can choose to follow or not participate in the study.

The intensity of Instagram Use. Participants were asked to open the "Activity" option on their respective Instagram accounts to measure Instagram use intensity. Through this option, a time measure that describes how high an individual's Instagram usage behavior is measured based on the average duration of Instagram usage per day (in hours and minutes) in the past week. In the questionnaire, participants were then instructed to report their average duration according to the number shown in the app when asked "How many hours a day do you use Instagram?"

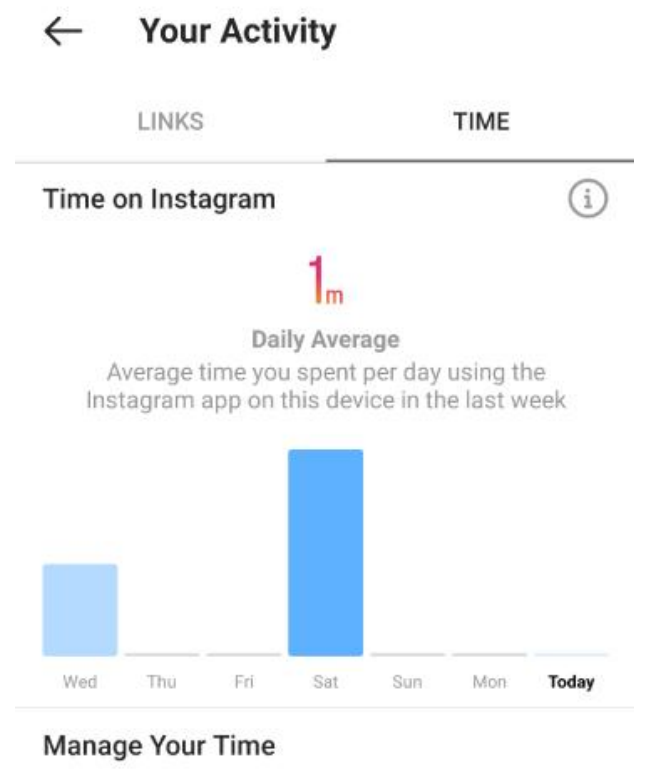

Figure I. "Your activity" feature on Instagram

Social Comparison. Two questions in the form of self-reports with a Likert scale format were used to measure participants' tendency to perform upward and downward social comparison behavior on Instagram. This question is adapted from Vogel et al. (2014), who examined social comparison behavior on Facebook (Table I). Psychometric analysis showed the measurement to be valid $(r=0.48)$ and reliable $(\alpha=0.7)$. 
Table I

Social comparison measurement

\begin{tabular}{|c|c|}
\hline & Item \\
\hline $\begin{array}{l}\text { Upward social } \\
\text { comparison }\end{array}$ & $\begin{array}{l}\text { When comparing yourself to others on Instagram, to what extent do you } \\
\text { focus on people who are better off than you? }\end{array}$ \\
\hline $\begin{array}{l}\text { Downward social } \\
\text { comparison }\end{array}$ & $\begin{array}{l}\text { When comparing yourself to others on Facebook, to what extent do you } \\
\text { focus on people who are worse off than you?" }\end{array}$ \\
\hline
\end{tabular}

The statements are, "When comparing yourself to others on Instagram, to what extent do you notice people who are better than you?" and "When comparing yourself to others on Instagram, to what extent have you noticed people who are worse off than you?" $(I=$ not at all; $5=$ very concerned).

Self-Esteem. Rosenberg Self-Esteem Scale or RSES (Rosenberg, 1965) was used to measure participants' self-esteem. The RSES measure contains ten items that assess global self-worth or overall self-worth by measuring the positive and negative feelings that individuals have about themselves. All items were answered using a 4-point Likert scale, ranging from I (strongly disagree) to 4 (strongly agree). The ten items are divided into five items that describe themselves positively and five items that describe themselves negatively.

Table 2

Sample items of Rosenberg Self-esteem Scale (Rosenberg, 1965) Sample item

Favorable Overall, I am satisfied with myself.

Unfavorable I feel like I don't have much to be proud of.

\section{Result}

Table 3 depicts the correlation between variables. Self-esteem is found to have a significant negative correlation with upward social comparison $r(158)=-0.319, p=<0.001$, whereby participants with poor self-evaluation tend to conduct upward social comparison in Instagram. Next, a significant positive correlation is found between upward social 
comparison and downward social comparison with $r(I 58)=0.372, p=<0.00 I$. This finding triggers the current researchers to conduct an additional analysis between upward and downward social comparison and self-esteem. The additional analysis can be found at the end of the result subsection. Further, the mediating analysis test using the bootstrap technique was done to determine whether social comparison mediates the effect of Instagram usage intensity towards self-esteem.

Table 3

Correlation between variables

\begin{tabular}{lllll}
\hline Variables & $\begin{array}{l}\text { Instagram } \\
\text { Use } \\
\text { Intensity }\end{array}$ & $\begin{array}{l}\text { Self- } \\
\text { Esteem }\end{array}$ & $\begin{array}{l}\text { Upward Social } \\
\text { Comparison }\end{array}$ & $\begin{array}{l}\text { Downward } \\
\text { Social } \\
\text { Comparison }\end{array}$ \\
\hline $\begin{array}{l}\text { Instagram use intensity } \\
\text { Self-Esteem }\end{array}$ & - & -0.020 & 0.013 & -0.018 \\
Upward Social Comparison & - & - & $-0.319 * * *$ & -0.094 \\
Downward Social Comparison & - & - & - & $0.372^{* * *}$ \\
\hline
\end{tabular}

$* * * p<.001$

In Model I, the predictor variable is the intensity of using Instagram, the criterion variable is self-esteem, and the intervening variable is upward social comparison. The analysis of model I shows that the $b$ path has a significant result, namely that upward social comparison can predict self-esteem $(b=-1.5,95 \% \mathrm{Cl}[-2.21,-0.80], t=-4.2, p=0.00$.). In other words, an increase in upward social comparison predicts reduced self-esteem.

The following result shows that the value of upward social comparison as a mediator is 0.00008 , and the $95 \%$ confidence interval $(\mathrm{Cl})$ ranges from -0.004 to 0.0035 . Because zero is included in the $95 \%$ confidence interval range, it can be concluded that upward social comparison is not able to be a mediator between the prediction of the intensity of Instagram use on self-esteem 


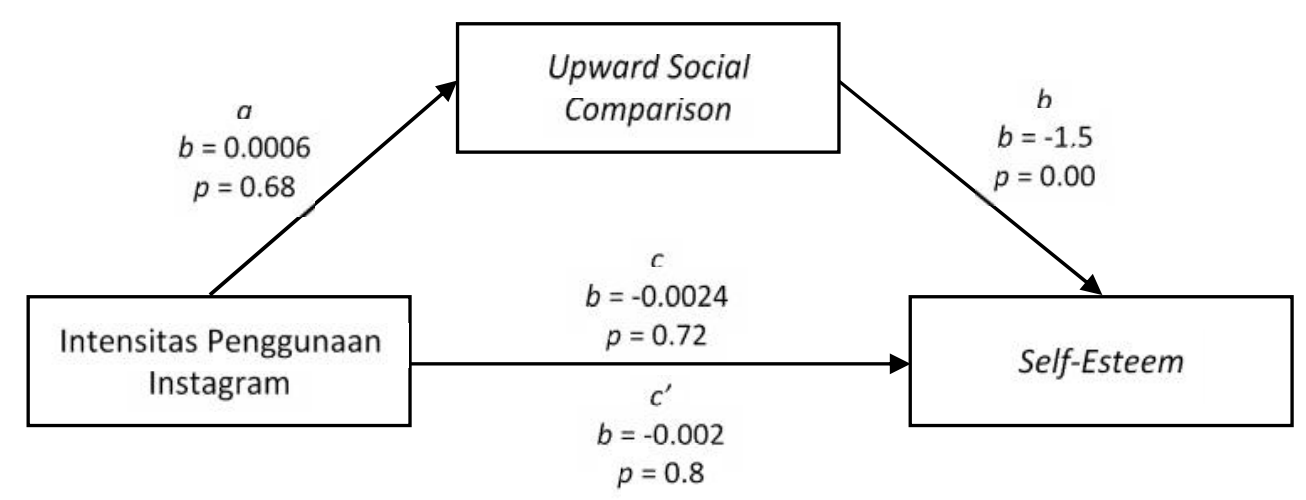

Model $I$. The mediation analysis for the intensity of using Instagram on self-esteem through upward social comparison

In model II, the predictor and criterion variable remains the same. However, the intervening variable is downward social comparison. Through the analysis results, the value of downward social comparison (M2) as a mediator is -0.00004 with a confidence interval $(\mathrm{Cl})$ of $95 \%$ ranging from -0.003 to 0.00 I. Therefore, it can be concluded that downward social comparison cannot be a mediator between the influence of Instagram use intensity on selfesteem.

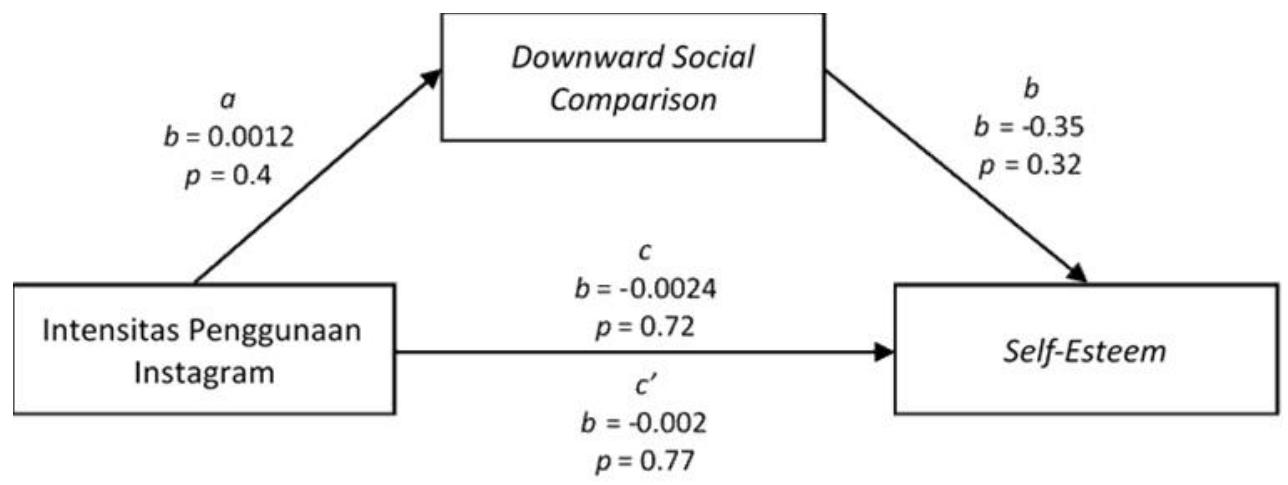

Model II. The mediation analysis of the intensity of the use of Instagram on self-esteem through downward social comparison 
In model III, the predictor variable is the downward social comparison, the criterion variable is self-esteem, and the intervening variable is the upward social comparison. Through model III, path a shows that downward social comparison is able to significantly predict upward social comparison, $b=0.04,95 \% \mathrm{Cl}[0.26,0.52], t=5.77, p=0.00$. Next, path $b$ shows that upward social comparisons can significantly predict self-esteem, b $=-1.64,95 \% \mathrm{Cl}[-2.42$, $0.86], t=-4.15, p=0.000 I$. The coefficient value $b>I$ indicates a solid prediction. Meanwhile, a negative $b$ value means that an increase in upward social comparison will be followed by a decrease in self-esteem.

The analysis results show that the value of upward social comparison as a mediator is -0.64 with a confidence interval $(\mathrm{Cl})$ of $95 \%$ ranging from -1.07 to -0.28 . The confidence interval range contains the real value of the research parameters, where it is assumed that the study sample is included in the $95 \%$ who have the true value. Therefore, it can be concluded that the b-value of the actual indirect effect falls in the range -1.07 and -0.28 . Since zero is not included in the $95 \%$ confidence interval range, it can be concluded that there is an indirect effect through upward social comparisons, which significantly affects the effect of downward social comparisons on self-esteem, b $=-0.64,95 \% \mathrm{BC}$ a $\mathrm{Cl}[-1.07,-0.28]$. This finding indicates that upward social comparison can mediate the effect of downward social comparison on self-esteem.

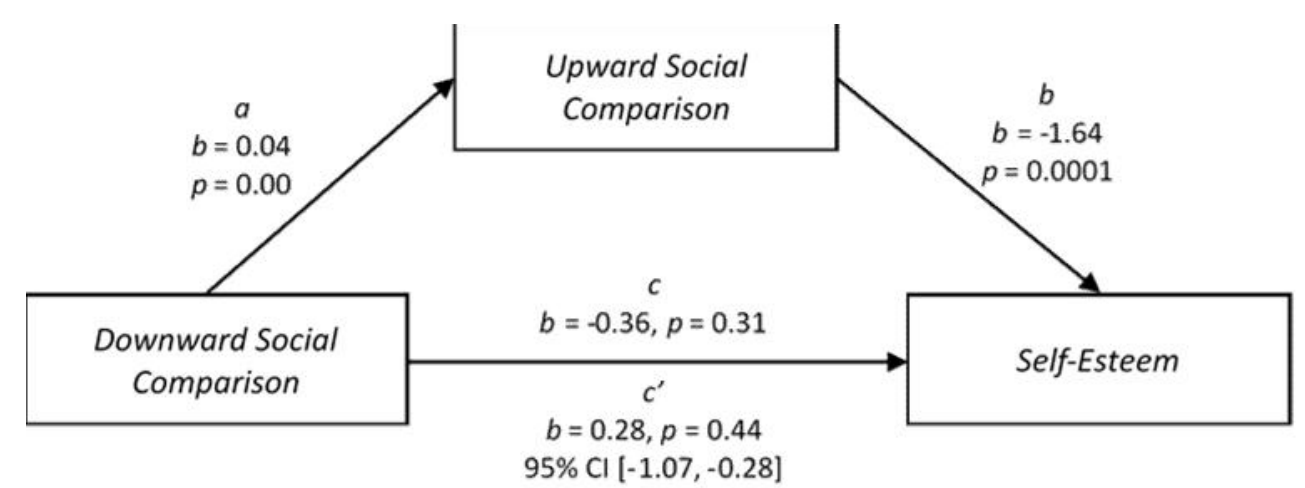

Model 4. Mediation analysis of Instagram's downward social comparison on self-esteem through upward social comparison 


\section{Discussion}

The study results found that upward and downward social comparisons were not able to be a mediator between the influences of the intensity of using Instagram on self-esteem significantly. The findings regarding upward social comparisons contradict to research by Vogel et al. (20l4), who found that upward social comparisons could mediate the influence of Facebook use intensity on users' self-esteem. One possibility that can cause differences in research results is the cultural differences in the research's participants. Vogel et al. (20I4) researched in the United States, which has an individualistic culture, in contrast to Indonesia, a collectivist culture. Based on the research of Sheldon, Rauschnabel, Antony, and Car (2017), there are differences in the behavior of using Instagram between individualistic and collectivist cultures. Users with an individualistic culture have a tendency to perceive their followers on Instagram as fans, frequently making users use Instagram as a medium to promote themselves. Self-promotion that is carried out can trigger other users to make the individual a target of social comparison. Apart from that, self-promotional content that is socially desirable can also affect users' self-esteem who see the content.

Conversely, users with a collectivist culture tend to use Instagram as a social interaction tool, where users perceive their followers on Instagram as social friends. This use will reduce the tendency of individuals to view other users as a social comparison target. Furthermore, it is stated that the gratuities received by users who adhere to a culture of individualism are significantly related to the duration of Instagram use. Therefore, the intensity of Instagram's use in an individualistic culture tends to be higher than that of a collectivist background.

Next, the upward social comparison was a significant and robust predictor of self-esteem, whereby an increase in upward social comparison behavior results in lower self-esteem. This finding is in line with a study by Chou and Edge (2012), who discovered that individuals who reported a high level of upward social comparison behavior in social media had adverse impacts that disrupted their self-esteem. Vogel et al. (2014) also stated that, with the increased use of SNS, most social comparison is upward in nature. This situation can partly be explained by the fact that users tend to show their ideal self on Instagram. As a result, on Instagram, users are exposed to more content that could create upward social comparison 
compared to the downward comparison. It is challenging to avoid this situation since Instagram is primarily filled with positive posts shown by others. The exposure to upward social comparison contents causes users to be more vulnerable to irrational perception and think that others are in a much happier state than themselves.

The impact of prolonged exposure to information or upward social comparison content on Instagram has terrible consequences for user self-esteem. Self-esteem itself is seen as an essential aspect in shaping a person's personality in the developmental phase of emerging adulthood (Srisayekti, Setiady, \& Sanitioso, 20I5). Social comparisons can help young adults find out the beliefs, preferences, and attitudes they want to maintain. However, it could also damage their sense of self-sufficiency when used to compare themselves with their peers on social media as an effort to self-evaluate.

Unexpectedly, this study found that the intensity of Instagram use could not predict upward or downward social comparisons. This finding contradicts the research of Arad, Barzilay, and Perchick (2017), which states that a high intensity of social media use will increase users' desire to conduct social comparisons. Conversely, one possibility that could explain this finding is that the level of self-esteem can influence an individual's tendency to compare himself with others (Bergagna \& Tartaglia, 2018). Individuals with low self-esteem have a high tendency to compare themselves with others in order to reduce self-insecurity, while individuals with high self-esteem tend to feel confident. In other words, the level of selfesteem has a significant influence on individuals' tendency to conduct social comparisons.

This explanation is also supported by Mulyani, Mikarsa, and Puspitawati (2018). They found that self-esteem is a significant predictor variable for Instagram addiction in adolescents. Low self-esteem values are stated to have a role in shaping addictive behavior towards Instagram. This study explains that users have a desire to continue using Instagram because they want to eliminate various negative emotions such as anxiety and helplessness, where these emotions can be associated with the characteristics of individuals with low selfesteem. Through this explanation, Mulyani, Mikarsa, and Puspitawati (2018) concluded that the frequency of Instagram use in individuals with low self-esteem will be higher. 
An exciting finding is found in additional analysis, namely downward social comparisons can predict upward social comparisons, while upward social comparisons can predict selfesteem. Through these results, it can be concluded that there is no relationship between downward social comparisons and self-esteem unless there is an upward social comparison as an intervening variable.

This study has several limitations, one of which is the measurement of upward and downward social comparisons, which are measured using only one item. According to Vogel and colleagues (2014), this can lead to possible errors in measurement. Furthermore, today many individuals have more than one Instagram account. However, the average duration of using Instagram is only obtained through one account, so the results are likely to be less accurate.

\section{Conclusion}

The results of this study indicate that upward social comparison and downward social comparison cannot significantly mediate the effect of the intensity of using Instagram on selfesteem. In general, Instagram is a useful social tool, offering various access to information and offering countless networking opportunities or social network expansion. Until now, the use of Instagram has continued to increase every year, and users have become increasingly dependent on Instagram for various kinds of daily activities. However, through this study's results, it was found that upward social comparisons can significantly predict selfesteem. Users are at risk of being exposed to high-intensity Instagram content, especially upward social comparison information that has a detrimental impact on users.

Moreover, previous research has shown that individuals who have low self-esteem often express themselves on Instagram as a place perceived as safe by users (Forest \& Wood, 20I2). This can result in a negative cycle of using Instagram to get social support. Users are increasingly showing themselves to upward social comparison information on Instagram, which can interfere with self-esteem so that the cycle starts all over again. 
Finally, for further research on similar topics, consider other aspects of Instagram's features, such as the number of followers, comments, and likes users receive. Although using Instagram is the most common method for measuring Instagram usage, these features also play an essential role in the social comparison process on Instagram.

\section{References}

Arad, A., Barzilay, O., dan Perchick, M. (2017). The impact of facebook on social comparison and happiness: Evidence from a natural experiment. SSRN Electronic Journal. doi:10.2139/ssrn.2916158.

Bergagna, E. dan Tartaglia, S. (20/8). Self-esteem, social comparison, and facebook use. Europe's Journal of Psychology, I4(4), 83I-845. doi:I0.5964/ejop.v| 4i4.I 592.

Boyd, D. M. \& Ellison, N. B. (2007). Social network sites: Definition, history, and scholarship. Journal of Computer-Mediated Communication, 12, 210-230. Doi: 10.1111/j.10836101.2007.00393.x

Chou, H. G. dan Edge, N. (20I2). They are happier and having better lives than I am: The impact of using facebook on perception of others' lives. Cyberpsychology, Behavior, and Social Networking, I5(2), II7-I 2 I. doi:10.1089/cyber.2011.0324.

Evelin, \& Adishesa, M. S. (2020). Hubungan Intensitas Penggunaan Instagram dan Self -Esteem pada Remaja. Jurnal Ilmiah Psikologi MIND SET, II(0I), 26 - 36. DOI: I0.358I4/mindset.vIIi0I.I297.

Festinger, L. (1954). A theory of social comparison processes. Human Relations, 7, II 7-I40. DOI: $10.1177 / 001872657400700202$.

Forest, A. L. \& Wood, J. V. (20I2). When social networking is not working: Individuals with low self-esteem recognize but do not reap the benefits of self-disclosure on Facebook. Psychological Science, 23, 295-302. DOI: 10.I I 77/09567976I I 429709.

Herman, J. (20|4). The ultimate beginner's guide to instagram. Kindle Edition.

Ivcevic, Z. \& Ambady, N. (2012). Personality impressions from identity claims on Facebook. Psychology of Popular Media Culture, I, 38-45. Doi: I0.1037/a0027329.

Jackson, C. A., dan Luchner, A. F. (2018). Self-presentation mediates the relationship between self-criticism and emotional response to Instagram feedback. Personality and Individual Differences, 133, I-6. doi:10.1016/j.paid.2017.04.052. 
Kaplan, A. M., dan Haenlein, M. (2010). Users of the world, unite! The challenges and opportunities of social media. Business Horizons, 53(I), 59-68. doi:10.1016/j.bushor.2009.09.003.

Lupinetti, V. M. (20I5). Self-presentation and social media: A qualitative examination of the use of instagram by amateur NPC female figure competitors. Master's Theses, San Jose State University, Kinesiology. Diakses dari http://scholarworks.sjsu.edu/etd_theses/4550.

Mulyani, I., Mikarsa, H. L., \& Puspitawati, I. (20I8, Maret 23). Perilaku adiksi pada instagram di kalangan remaja. Dipresentasikan dalam Seminar Nasional Pascasarjana di Universitas Gadjah Mada, Yogyakarta, Indonesia.

Nadkarni, A. \& Hoffmann, S. G. (20I2). Why do people use Facebook? Personality and Individual Differences, 52, 243-249. Doi: 10.1016/j.paid.20II.11.007.

Rinn, A. N., Jamieson, K. M., Gross, C. M., dan McQueen, K. S. (2009). A canonical correlation analysis of the influence of social comparison, gender, and grade level on the multidimensional self-concepts of gifted adolescents. Soc Psychol Educ, I2, 25I-269.

Rosenberg, M. (1965). Society and the adolescent self-image. Princeton, NJ: Princeton University Press.

Royal Society for Public Health. (2017). Instagram ranked worst for young people's mental health. Available from https://www.rsph.org.uk/about-us/news/instagram-rankedworst-for-young-people-s-mental-health.html (diakses pada tanggal 25 Februari 2019)

Sheldon, P., Rauschnabel, P. A., Antony, M. G., dan Car, S. (2017). A cross-cultural comparison of Croatian and American social network sites: Exploring cultural differences in motives for Instagram use. Computers in Human Behavior, 75, 643-65I. doi:10.1016/j.chb.2017.06.009.

Srisayekti, W., Setiady, D. A., \& Sanitioso, R. B. (20I5). Harga diri (self-esteem) terancam dan perilaku menghindar. Jurnal Psikologi, 42(2), I4I-I56.

Tosun, L. P. (2012). Motives for Facebook use and expressing the "true self" on the Internet. Computers in Human Behavior, 28, 11510-1517. Doi: 10.1016/j.chb.2012.03.018.

Vogel, E. A., Rose, J. P., Roberts, L. R., dan Eckles, K. (20I4). Social comparison, social media, and self-esteem. Psychology of Popular Media Culture, 3(4), 206-222. doi:10.1037/ppm0000047. 